\title{
High-resolution Imaging of Fault Zone Structures with Seismic Fault Zone Waves
}

by Yehuda Ben-Zion, Zhigang Peng, Michael Lewis, and Jeff McGuire

doi:10.2204/iodp.sd.s01.23.2007

Large fault zone (FZ) structures with damaged rocks and material discontinuity interfaces can generate several indicative wave propagation signals. High crack density may produce prominent scattering and non-linear effects. A preferred crack orientation can lead to shear wave splitting. A lithology contrast can produce $\mathrm{FZ}$ head waves that propagate along the material interface with the velocity and motion polarity of the faster medium. A coherent low velocity layer may generate $\mathrm{FZ}$ trapped waves. These signals can be used to obtain high-resolution imaging of the subsurface structure of fault zones, and to track possible temporal evolution of FZ material properties. Several results have emerged from recent systematic analyses of such signals. The trapped waves are generated typically by $\sim 100$-m-wide layers that extend only to $\sim 3-4 \mathrm{~km}$ depth and are characterized by $30 \%-50 \%$ velocity reduction and strong attenuation (Ben-Zion et al., 2003; Lewis et al., 2005; Peng et al., 2003). The trapping structures appear to be surrounded by broader anisotropic and scattering zones limited primarily to the shallow crust (Fig. 1). Results associated with anisotropy and scattering around the North Anatolian fault using repeating earthquake clusters do not show precursory temporal evolution (Peng and Ben-Zion, 2004, 2005, 2006). The anisotropy results show small co-seismic changes, while the scattering results show larger co-seismic changes and post-seismic logarithmic recovery. The temporal changes probably reflect damage evolution in the top few hundred meters of the crust. Systematic analyses of head waves along several sections of the San Andreas fault reveal material interfaces that extend to the bottom of the seismogenic zone (Ben-Zion and Malin, 1991; McGuire and Ben-Zion, 2005). Joint arrival time inversions of direct and $\mathrm{FZ}$ head waves and waveform modeling imply (Fig. 2) velocity contrasts of $20 \%$ or more in the top $3 \mathrm{~km}$ and lower contrasts of $5 \%-15 \%$ in the deeper section (Ben-Zion et al., 1992; Lewis et al., 2007). In several places, analyses of trapped and head waves indicate that the shallow damaged layers are asymmetric across the fault (Lewis et al., 2005, 2007). The observed damage asymmetry may reflect preferred propagation direction of earthquake ruptures (Ben-Zion and Shi, 2005).

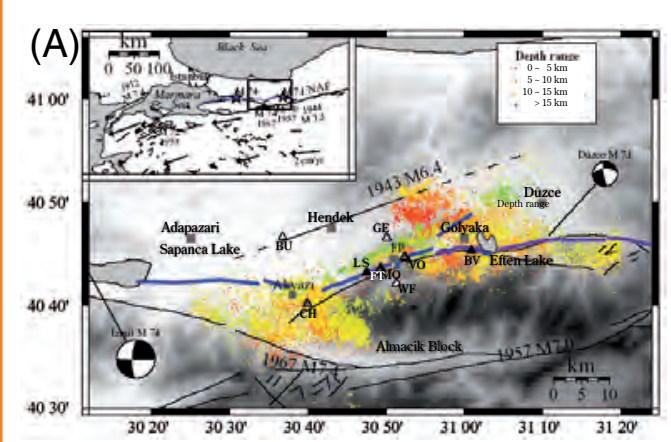

(B) Fault zone trapped waves

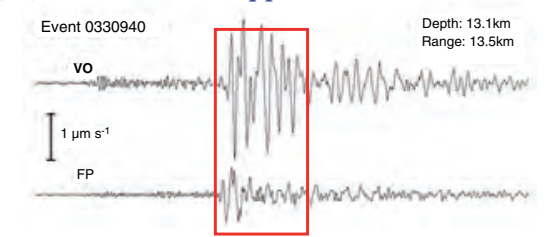

(C)

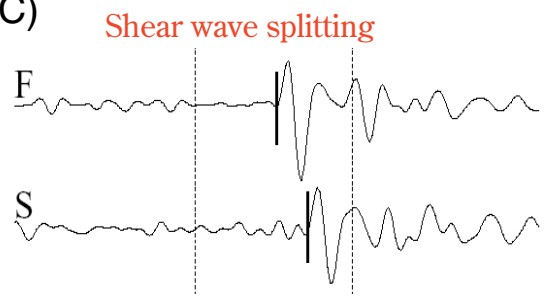

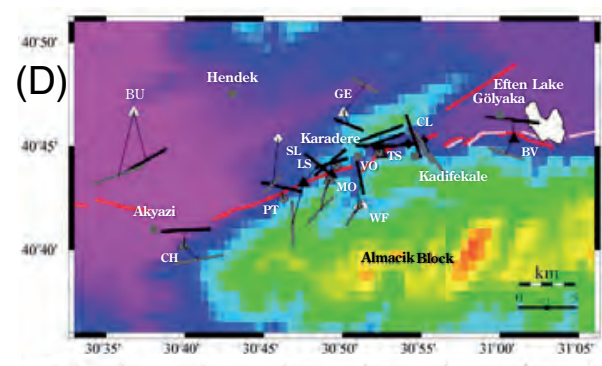

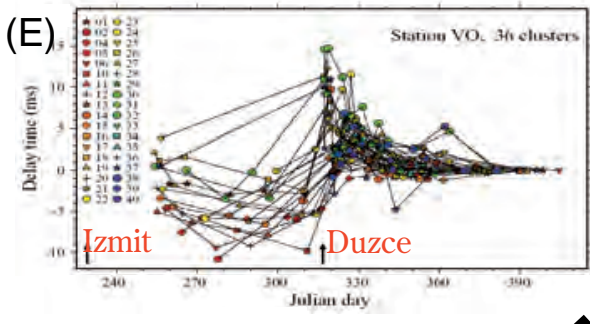

(F)

$$
\sim 100 \text { m wide }
$$

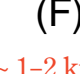

$1-2 \mathrm{~km}$ wide anisotropic layér

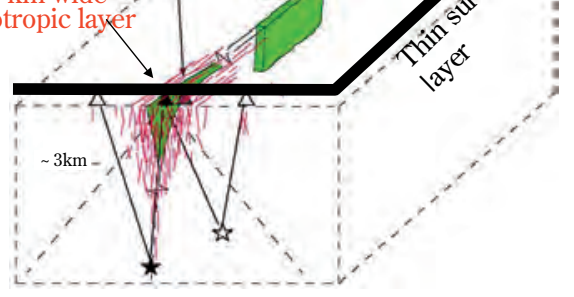

Figure 1. [A] Hypocentral distribution of $\sim 18,000$ earthquakes recorded by the PASSCAL seismic experiment along the KaradereDüzce branch of the north Anatolian fault. [B] An example of FZ waveforms recorded by stations on (VO) and off (FP) the fault. [C] An example of rotated horizontal seismograms showing split shear waves. [D] A summary plot of average splitting parameters (bars) in our study area. The bars are oriented parallel to the average fast direction and scaled by the average delay time. [E] Median delay times for the early S-coda waves plotted against the earthquake occurrence times for the vertical-component seismograms generated by 36 repeating clusters and recorded at station VO. [F] A schematic summary of the fault zone model around the study area. Panels $[\mathrm{A}]$ and $[\mathrm{B}]$ are from Ben-Zion et al., (2003). Panels [C] and [D] are from Peng and Ben-Zion (2004, 2005). Panel $[E]$ is from Peng and BenZion (2006). 

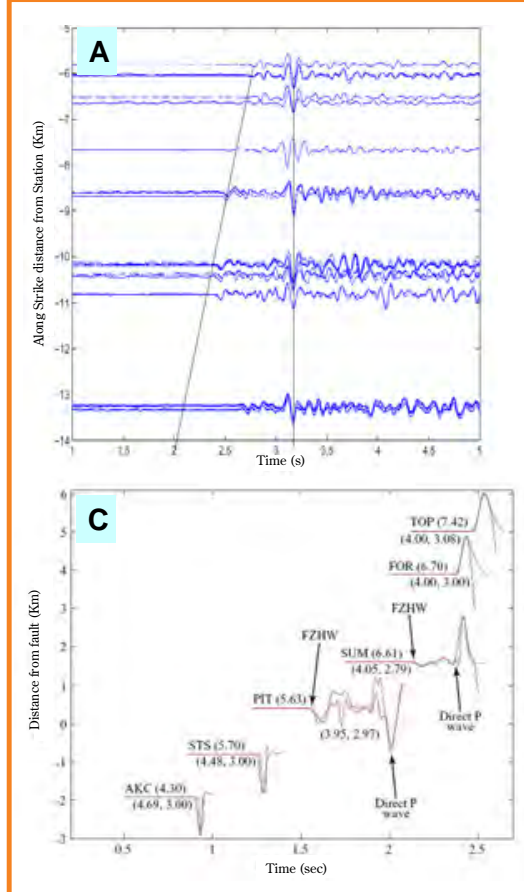

\section{Acknowledgments}

The discussed studies were supported by the NSF, USGS and SCEC.

\section{References}

Ben-Zion, Y. and Malin, P., 1991. San Andreas fault zone head waves near Parkfield, California. Science, 251:1592-1594, doi:10.1126/science.251.5001.1592.

Ben-Zion, Y. and Shi,Z., 2005. Dynamic rupture on a material interface with spontaneous generation of plastic strain in the bulk. Earth Planet. Sci. Lett., 236:486-496, doi: 10.1016/j. eps1.2005.03.025.

Ben-Zion, Y., Katz, S., and Leary, P., 1992. Joint inversion of fault zone head waves and direct $\mathrm{P}$ arrivals for crustal structure near major faults. J. Geophys. Res., 97:1943-1951.

Ben-Zion, Y., Peng, Z., Okaya, D., Seeber, L., Armbruster, L.G., Ozer, N., Michael, A.J., Baris, S., and Aktar, M., 2003. A shallow fault zone structure illuminated by trapped waves in the Karadere-Duzce branch of the North Anatolian Fault, western Turkey. Geophys. J. Int., 152:699-717, doi:10.1046/ j.1365-246X.2003.01870.x.

Lewis, M.A, Ben-Zion, Y., and McGuire, J., 2007. Imaging the deep structure of the San Andreas Fault south of Hollister with joint analysis of fault-zone head and direct $P$ arrivals. Geophys. J. Int., 169, 1028-1042, doi:10.111/j.1365246X.2006.03319.X.

Lewis, M.A, Peng, Z., Ben-Zion, Y., and Vernon, F., 2005. Shallow seismic trapping structure in the San Jacinto fault zone. Geophys. J. Int., 162:867-881, doi:10.1111/j.1365246X.2005.02684.x.

McGuire, J. and Ben-Zion, Y., 2005. High-resolution imaging of the Bear Valley section of the San Andreas Fault at seismogenic depths with fault-zone head waves and relocated seismicity.
Figure 2. $[A]$ Vertical component $P$ waveforms at Northern California Seismic Network (NCSN) station BHR northeast of the San Andreas Fault (SAF) south of Hollister with direct body wave (vertical line) and first arriving fault zone head wave (diagonal line). [B] Inversion results of $P$ wave velocity contrast across the SAF versus depth from arrival times of head and direct waves. The solid red and blue lines are the best-fitting velocity profiles for the slow and fast sides of the fault, respectively, out of 10 inversion runs. The dashed red and blue lines are the average depth and velocity of each layer, respectively, from the 10 inversions, and the grey shaded areas around the means represent the standard deviation of the depth and velocity of that layer. The dashed black line is the initial velocity and depth model used in the inversion. The dashed gray line (top horizontal axis) gives the number of events as a function of depth. [C] Example of synthetic waveform fits (red) for observed seismograms (blue) for stations on the fast and slow sides of the SAF. Some of the direct $P$ and head wave arrivals are indicated by arrows with corresponding labels. The average $P$ wave velocities in $\mathrm{km} \mathrm{s}^{-1}$ of the crustal block used to generate the synthetic seismograms are given in parentheses under the waveforms. [D] A schematic diagram of the inferred velocity structure of the SAF south of Hollister, consisting of two layered quarter-spaces, joined along a sharp material interface, and a shallow asymmetric low velocity zone around the fault. Panel $[A]$ is from McGuire and Ben-Zion (2005). Panels [B]-[D] are from Lewis et al., (2007).

Geophys. J. Int., 163:152-164, doi:10.1111/j.1365246X.2005.02703.x.

Peng, Z. and Ben-Zion, Y., 2004. Systematic analysis of crustal anisotropy along the Karadere-Düzce branch of the north Anatolian fault. Geophys. J. Int., 159:253-274, doi:10.1111/ j.1365-246X.2004.02379.x.

Peng, Z. and Ben-Zion, Y., 2005. Spatio-temporal variations of crustal anisotropy from similar events in aftershocks of the 1999 M7.4 İzmit and M7.1 Düzce, Turkey, earthquake sequences. Geophys. J. Int., 160(3):1027-1043, doi:10.1111/j.1365246X.2005.02569.x.

Peng, Z. and Ben-Zion, Y., 2006. Temporal changes of shallow seismic velocity around the Karadere-Duzce branch of the north Anatolian fault and strong ground motion. Pure Appl. Geophys., 163:567-600, doi:10.1007/s00024-005-0034-6.

Peng, Z., Ben-Zion, Y., Michael, A.J., and Zhu, L., 2003. Quantitative analysis of seismic trapped waves in the rupture zone of the 1992 Landers, California earthquake: Evidence for a shallow trapping structure. Geophys. J. Int., 155:1021-1041, doi:10.1111/j.1365-246X.2003.02109.x.

\section{Authors}

Yehuda Ben-Zion, Department of Earth Science, University of Southern California, Los Angeles, 90089, Calif., U.S.A., email: benzion@usc.edu.

Zhigang Peng, School of Earth and Atmospheric Sciences, Georgia Institute of Technology, Atlanta, Ga., 30332-0340, U.S.A.

Michael Lewis, Department of Earth Science, University of Southern California, Los Angeles, 90089, Calif., U.S.A.

Jeff McGuire, Department of Geology and Geophysics, Woods Hole Oceanographic Institution, Woods Hole, Mass., 02543, U.S.A. 